\title{
Effectiveness of Core Muscle Strengthening using Swiss Ball vs Traditional Core muscle Strengthening Exercises on Functional Impairments in Amateur Marathon Runners with Patellofemoral Pain Syndrome
}

\author{
Simran R. Sachadev *1, Ronald N Prabhakar ${ }^{2}$, Manal M Anthikat ${ }^{3}$. \\ ${ }^{* 1}$ Intern, Miraj Medical Center, College Of Physiotherapy, Wanless Hospital, Miraj, Sangli \\ district of Maharashtra, India. \\ ${ }^{2}$ PhD Scholar, Department of Musculoskeletal Physiotherapy, Miraj Medical Center, College Of \\ Physiotherapy, Wanless Hospital, Miraj, Sangli district of Maharashtra, India. \\ ${ }^{3}$ Assistant Professor, Department of Neurosciences, Miraj Medical Center, College Of Physio- \\ therapy, Wanless Hospital, Miraj, Sangli district of Maharashtra, India.
}

\section{ABSTRACT}

Background: Devashee S Mistry discovered that the prevalence of anterior knee pain in marathon runners is $68 \%$ in the age group of 15-30 years. There are many literatures that shows correlation between core muscle instability and pain associated with Patellofemoral Pain Syndrome (PFPS). Although, there are many studies done to study the effectiveness of core muscle strengthening program on pain and functional impairment in general population with PFPS, there are only few literatures which evaluates its effectiveness on marathon runners.

Study purpose/ Research Question: The purpose of this study is to compare the effectiveness of core muscle strengthening using Swiss ball versus traditional core muscle exercises on mat for managing the functional impairments in the amateur marathon runners with PFPS.

Material and methodology: Amateur marathon runners with patellofemoral pain syndrome $(n=32)$ having anterior knee pain were included in this study. A comparative study was done where two group were made. Group $A(n=16)$ received core strengthening exercises using swiss ball and group $B(n=16)$ received traditional core strengthening exercises using mat. Both groups received conventional Physiotherapy intervention which included hot moist pack applied on anterior aspect of knee (10 minutes), strengthening for lower limb muscles and stretching for lower limb muscles, 10 seconds hold for each muscle for 3 repetitions. Treatment was given for 3 times a week, for 4 weeks. Pain and other functional impairment such as squatting, stair climbing, walking and running were assessed using VAS and Patellofemoral Pain Severity Scale.

Results: Group A showed significant decrease in pain and functional impairments as compared to group B. Mean pre VAS of group A was 6.94 which was significantly higher than mean post VAS $1.60(p<0.001)$. Mean pre VAS of group B was 6.88 which was significantly higher than mean post VAS $2.71(p<0.001)$. Mean pre Patellofemoral pain Severity Scale of group A was 72.56 which is significant higher than post Patellofemoral Pain Severity Scale $15.87(p<0.001)$. Mean pre Patellofemoral Pain Severity Scale of group B was 74.31 which is significantly higher than post mean Patellofemoral Pain Severity Scale $33.12(p<0.001)$

Conclusion: Core muscle strengthening using swiss ball is more effective than traditional core muscle strengthening using mat in amateur marathon runners for reducing pain and functional impairments having PFPS KEY WORD: Anterior knee pain, Marathon runners, Patellofemoral, Runner's knee.

Address for correspondence: : Simran R. Sachadev, PT, Krishnakunj, Near Sai Nandan park, Miraj, Sangli district of Maharashtra, India. E-Mail: simransachdev870@gmail.com

International Journal of Physiotherapy and Research

ISSN (E) 2321-1822 | ISSN (P) 2321-8975

https://www.ijmhr.org/ijpr.html

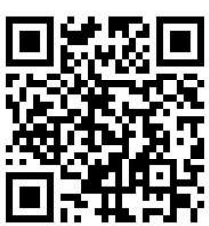

DOI: $10.16965 /$ ijpr.2021.153

DOI-Prefix: https://dx.doi.org/10.16965/ijpr

\section{Article Information}

Received: 09 Jun 2021

Peer Review: 09 Jun 2021

Revised: None
Accepted: 13 Jul 2021

Published (O): 11 Aug 2021

Published (P): 11 Aug 2021 


\section{INTRODUCTION}

Patellofemoral pain syndrome (PFPS) is one amongst the foremost prevalent and most arduous injuries a marathon runner could face that is characterized by anterior knee pain which aggravates throughout the loading activities [1]. Anterior knee pain is found in each twenty two out of a thousand people every year $[1,2]$. Young females are twice as affected as young males. Patellofemoral pain syndrome (PFPS) is the potential explanation for anterior knee pain [3-5]. PFPS is encountered in outpatient setting in adolescents and in people less than 60 years old [2]. Pain in and around the knee that intensifies for the duration of loading sports is the cardinal characteristic of PFPS [3]. Prolonged sitting with knee bent and / descending stairs can be a trigger in PFPS [1]. Pain with squatting is the maximum sensitive physical examination finding $[5,6]$. The contributing reasons may be diagnosed by analysing a patient's gait, posture, footwear [5]. Activities which include squatting, hiking up and down, strolling make a contribution as risk factors for development of PFPS [8]. Along with that female gender, dynamic valgus, foot abnormalities, overuse, quadriceps weakness, patellar instability are the mounted risk factors [3].

Many studies recommend that PFPS shows no important structural injury of the knee or changes within the Q-angle as such $[3,4,6]$. Purposeful malalignment which means patellar maltracking and dynamic valgus (due to weakness of lower limb muscles) [3]. The development of PFPS is multifactor with lower extremity functional disorders [3]. The literature conjointly provides the evidence for association of core muscle instability with PFPS [3]. There are several well outlined pathologies that leads to PFPS. Patellar maltracking is one of the causes for PFPS. Wilson NA, Press $\mathrm{JM}$, Koh JL, Hendrix RW, Zhang LQ demonstrated significant increased lateral translation in patients with PFPS doing squats using an optoelectronic motion capture system and skin marker [2]. Another reason behind PFPS is imbalance of the muscles such as M.vastus medialis and $\mathrm{M}$. vastas lateralis. Pal $\mathrm{S}$, draper CE, Frederiscson M, Gold GE correlate delayed activation of the $M$. vastus lateralis and $M$. vastus medialis with PFPS. Rauh MJ, KOEPSELL td, Rivara FP, Rice SG, Margherita AJ reported that cross-country runners had augmented $Q$ angle that are additional liable to injuries [2].

On the contrary, Park SK, Stefanyshyn DJ have studied that PFPS and increased Q-angle aren't related which makes maltracking of patella and imbalanced activation of vastus lateralis and medialis the cause of PFPS [2]. Patients with PFPS have shown rather a dynamic malalignment than structural fault. Myer JD, Ford KR, Barber Foss KD, Goodman A in their study demonstrated that athletes with acute PFPS showed increased abduction of affected knee [4]. Hip muscle instability and hip abductor weakness is likewise a cause for development of PFPS. Recent research have proven that functional malalignment is due to abductor and external rotator muscles and does not only arise in the knee joint [4]. Padua DA, Marshall SW, Beutler AL, discovered out that weakness of hip abductors is associated with PFPS [12]. Iliotibal tract controls patellar tracking $\mathrm{Wu} \mathrm{CC}$, Shih $\mathrm{CH}$ demonstrated that the length of IT band has influence on dynamic valgus of the knee [4]. Overload of the Patellofemoral joint is a probable trigger for PFPS $[10,13]$. Functional lateralization of the patella and dynamic valgus combined with overload of Patellofemoral joint leads to overuse of the structure of Patellofemoral joint [8]. PFPS is also called as runner's knee. Devashree $S$ Mistry, et al in their study "Prevalence of Anterior Knee Pain in Marathon Runners" concluded that in the age group of $15-30$ years marathon runners prevalence of anterior knee pain was $68 \%$ [6]. The foundation to athletic activities is "Core". It stabilizes the hips and spine when athletes run, jump or cut [7]. It also helps to accelerate and decelerate the forces created during sports activities [7]. If the core is weak the ligaments start to get strained, muscles of the lower limb fatigues faster which diminishes the performance, most affected joint in this scenario is the knee, which leads to pain [14]. There are several literatures describing strong correlation between core muscle instability and its affection on the lower extremity function [6-10]. 
Bouisset et. Al proposed theories regarding relationship between lower extremity function, performance and core stability suggesting that postural support in the form of motor activity occurs before the voluntary extremity movements [13]. The evidence for this study was provided by Hodges et. Al using fine wire EMG to record recruitment of the abdominal muscles and multifidus during lower extremity voluntary movement [13]. They discovered that regardless of the direction of the movement, trunk muscle activity occurs before the activity of lower limb agonists [13]. Specifically, the transverses abdominis was the first muscle to be activated in the preparation for lower extremity movement. Hence the authors concluded that core muscle creates a stale foundation, through cocontraction, for lower extremity function [13].

Core muscle strength has an influence on structures from the ankle to the low back ${ }^{5-8}$. However, not every lower limb injury is caused due to core muscle weakness $[12,13]$. Perhaps, knee joint is the most influenced joint by core instability [16]. Females within the age group 12-21 with PFPS were studied by Ireland et al. hip strength were recorded using strap stabilization and hand held dynamometer [8]. The author discovered that there was reduced hip strength in the subjects and he suggested that this weakness may represent a diminished capability to resist movement into knee internal rotation and adduction and positions associated with retropatellar contact pressure [12]. Similarly, Fredericson et al in their study of marathon runners with IT-band friction syndrome suggested that there is core instability and decreased hip muscle strength as compared to uninvolved hip [12].

Following a 6 week core strengthening program, near about $92 \%$ of the affected group were pain free [12].

Core muscle strengthening using swiss have been studied and proven to be more effective than traditional mat core strengthening. There are no literatures that compare the effectiveness of core muscle strengthening using swiss ball over traditional mat core exercises in amateur marathon runners with PFPS. Hence, there is lack of evidence of effectiveness of core muscle strengthening using swiss ball in marathon runners with PFPS. So, the need of the study arises.

The aim of this study is to compare the effectiveness of core strengthening using ball versus traditional mat core strengthening in amateur marathon runner with PFPS (15-30 years).

\section{MATERIAL AND METHODOLOGY}

Ethical clearance from ethics committee was taken, prior to the initiation of study. The study was conducted among the amateur marathon runners age ranging between 15 to 30 years. The sample size was 32 . Data was collected from tertiary health care centre. The purpose of this study was explained in vernacular language and the individuals were screened according to the inclusion and exclusion criteria. Individuals were allocated in two groups i.e. $A(n=16)$ and $B(n=16)$ by envelope method. Written informed consents were signed by the selected participants. Pre- interventional VAS score and Patellofemoral Pain Severity Scale (PPSS) were recorded. After 4 weeks of intervention for both the groups, data was recorded and analyzed.

Statistical analysis: Data was analyzed using SPSS version 18 . The results were considered significant ' $p$ ' value being $<0.005$ and confidence interval $(\mathrm{Cl})$ at $95 \%$. Parametric tests, Paired and Unpaired ' $t$ ' test were done for intra and inter-group analysis respectively.

Procedure: Assessment of the pain was evaluated by asking the participants to rate the severity of anterior knee pain on VAS from 1 to 10 and on Patellofemoral Pain Severity Score (PPSS) scale and recorded. In group A core muscle strengthening program using swiss ball was taught to the participants, followed by conventional physiotherapy in the form of hot moist pack over anterior aspect of the knee, stretching to lower limb muscles (30 sec hold, 3 times) and strengthening to lower limb muscles. All the exercises in group A were performed for 3 times in a week, for 4 weeks. Core muscle strengthening using swiss ball included 4 exercises: supine hip twists, static 
abdominal marching, bridging and abdominal crunches (on swiss ball). The progressions in the sets were made weekly (table 1 ). In group $B$ traditional core exercises on mat were taught to the participants, followed by conventional physiotherapy same as group A. Total 12 session were performed same as group $A$ i.e. for 4 weeks, 3 times a week. The progressions of the sets were made weekly( table 2). Traditional mat core strengthening program included: bird dog exercise, bridging, Russian twists using medicine ball and abdominal crunches. Both the exercise programs were planned in such a way to avoid the bias between the groups. Each session lasted for about 28-35 minutes for both the groups. Pain assessment using VAS and functional assessment using PPSS was done after every session.

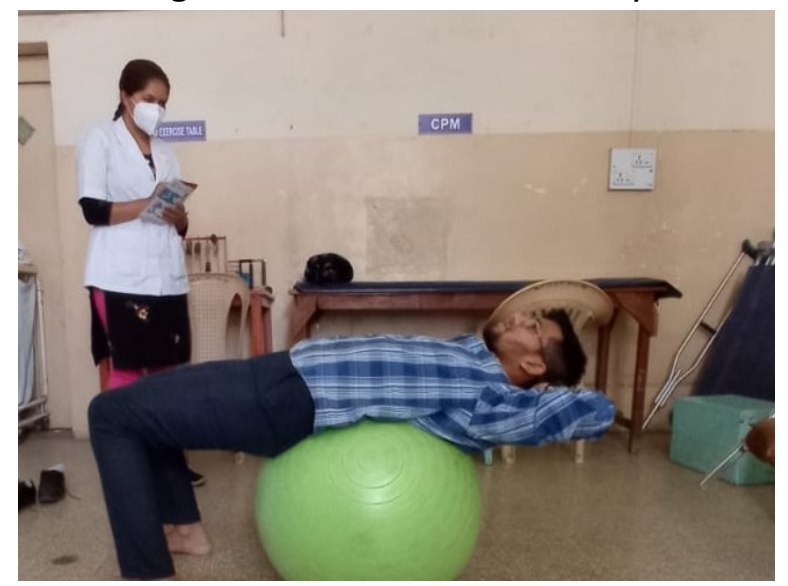

Participant performing abdominal crunches on swiss ball.

\section{RESULTS}

Total 32 eligible amateur marathon runners were recruited in the study. Data was analyzed by taking 16 participants in group $A$ and 16 in group B respectively. Anthropometric data of subjects at baseline show non significance differences (table 3). Table 4 and fig. 1 shows that total 19 (59.37\%) subjects were affected with right side PFPS and 13 (40.63\%) subjects were affected with left side PFPS.

Table 5 and 6 shows that Mean pre VAS of group A was $6.943 \pm 0.67$ and Mean pre VAS of group $B$ was $6.887 \pm 0.51$. Mean post VAS of group A was $1.6062 \pm 0.72$ which was significantly lower than Mean post VAS of group B i.e. $2.7063 \pm 5.67$. The difference in Means of VAS (pre and post) in both the groups was 5.3376 and 4.1812 respectively $(p<0.001)$, suggesting that anterior knee pain reduced significantly in both the groups but reduced more in group $A$ (core strengthening using swiss ball). Likewise, Mean pre PPSS in group A was $72.563 \pm 7.52$ and Mean pre PPSS of group $B$ was $74.31 \pm 5.22$. Mean post PPSS in group $A$ was $15.88 \pm 5.67$ which was significantly lower than mean Post PPSS of group B i.e. $33.12 \pm 5.39$. The difference in Mean of PPSS (pre and post) in both groups was 56.683 and 41.190 suggesting that there was reduction in functional impairments in both the groups but more in group $A$.

Table 1: Core strengthening using swiss ball for group $A$.

\begin{tabular}{|c|c|c|c|c|}
\hline \multirow{12}{*}{ Group A } & Week 1 & Week 2 & Week 3 & Week 4 \\
\hline & Supine hip twists & Supine hip twists & Supine hip twists & Supine hip twists \\
\hline & 10 on each side & 12 on each side & 14 on each side & 16 on each side \\
\hline & 3 sets & 3 sets & 3 sets & 3 sets \\
\hline & Static ab. Marching & Static ab. Marching & Static ab. Marching & Static ab. Marching \\
\hline & 20 repetition & 25 repetition & 30 repetition & 35 repetition \\
\hline & 3 sets & 3 sets & 3 sets & 3 sets \\
\hline & Bridging & Bridging & Bridging & Bridging \\
\hline & 1 minute & 2 minutes & 3 minutes & 4 minutes \\
\hline & Abdominal crunches & Abdominal crunches & Abdominal crunches & Abdominal crunches \\
\hline & 10 repetition & 12 repetition & 14 repetition & 16 repetition \\
\hline & 3 sets & 3 sets & 3 sets & 3 sets \\
\hline
\end{tabular}


Table 2: Traditional Core Strengthening program for group B.

\begin{tabular}{|c|c|c|c|c|}
\hline \multirow{10}{*}{ Group B } & Week 1 & Week 2 & Week 3 & Week 4 \\
\hline & 10 on each side & 12 on each side & 14 on each side & 16 on each side \\
\hline & 3 sets & 3 sets & 3 sets & 3 sets \\
\hline & 20 repetition & 25 repetition & 30 repetition & 35 repetition \\
\hline & 3 sets & 3 sets & 3 sets & 3 sets \\
\hline & Bridging & Bridging & Bridging & Bridging \\
\hline & 1 minute & 2 minutes & 3 minutes & 4 minutes \\
\hline & Abdominal crunches & Abdominal crunches & Abdominal crunches & Abdominal crunches \\
\hline & 10 repetition & 12 repetition & 14 repetition & 16 repetition \\
\hline & 3 sets & 3 sets & 3 sets & 3 sets \\
\hline
\end{tabular}

Table 3: Anthropometric data of participants at baseline.

\begin{tabular}{cccccc}
\hline \multirow{2}{*}{$\begin{array}{c}\text { Demographic } \\
\text { data }\end{array}$} & \multicolumn{2}{c}{ Mean(SD) } & \multirow{2}{*}{ value of ' $\mathrm{t}$ ' } & value of ' $\boldsymbol{p}$ ' & Significance \\
\cline { 2 - 3 } Age & Group A & Group B & & & \\
\hline
\end{tabular}

Table 4: Distribution of sides of subjects with PFPS receiving core strengthening along with conventional physiotherapy.

\begin{tabular}{cccccccc}
\hline \multirow{2}{*}{ Side } & \multicolumn{2}{c}{ Group A } & \multicolumn{2}{c}{ Group B } & \multicolumn{2}{c}{ Total } \\
\cline { 2 - 7 } & Frequency & $\%$ & Frequency & $\%$ & Frequency & $\%$ \\
Left & 6 & 37.5 & 7 & 43.75 & 13 & 40.63 \\
Right & 10 & 62.5 & 9 & 56.25 & 19 & 59.37 \\
Total & 16 & 100 & 16 & 100 & 32 & 100 \\
\hline & & & & & Mean VAS & \\
\cline { 2 - 6 } & & Group & N & Pre & Post & Difference \\
\hline
\end{tabular}

Table 5: Descriptive intragroup statistics of participants using paired t test.

\begin{tabular}{|c|c|c|c|c|c|}
\hline A & & 16 & $6.9438 \pm 0.67$ & $1.6062 \pm 0.72$ & 5.3376 \\
\hline \multicolumn{6}{|c|}{ Mean PPSS } \\
\hline A & & 16 & $72.563 \pm 7.52$ & $15.88 \pm 5.67$ & 56.683 \\
\hline \multicolumn{6}{|c|}{ Mean VAS } \\
\hline GROUP & & $\mathbf{N}$ & Pre & Post & Difference \\
\hline B & & 16 & $6.8875 \pm 0.51$ & $2.7063 \pm 5.67$ & 4.1812 \\
\hline \multicolumn{6}{|c|}{ Mean PPSS } \\
\hline B & & 16 & $74.31 \pm 5.22$ & $33.12 \pm 5.39$ & 41.19 \\
\hline \multicolumn{6}{|c|}{ Mean VAS } \\
\hline Group & $\mathbf{N}$ & & Pre & Post & Difference (mean) \\
\hline A & 16 & & $6.9438 \pm 0.67$ & $1.6062 \pm 0.72$ & 5.3376 \\
\hline B & 16 & & $6.8875 \pm 0.51$ & $2.7063 \pm 0.40$ & 4.1812 \\
\hline \multicolumn{6}{|c|}{ Mean PPRS } \\
\hline Group & $\mathbf{N}$ & & Pre & Post & Difference ( mean) \\
\hline A & 16 & & $72.563 \pm 7.52$ & $15.88 \pm 5.67$ & 56.683 \\
\hline B & 16 & & $74.31 \pm 5.22$ & $33.12 \pm 5.39$ & 41.19 \\
\hline
\end{tabular}

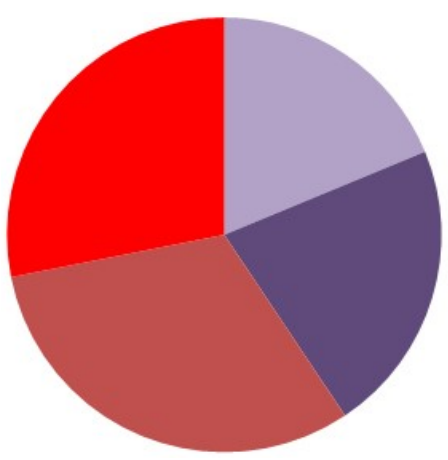

- LEFT (GROUP A)

LEFT(GROUP B)

RIGHT ( GROUP A)

RIGHT (GROUP B)
Fig 1: Distribution of sides of subjects with PFPS receiving core strengthening along with conventional physiotherapy. 


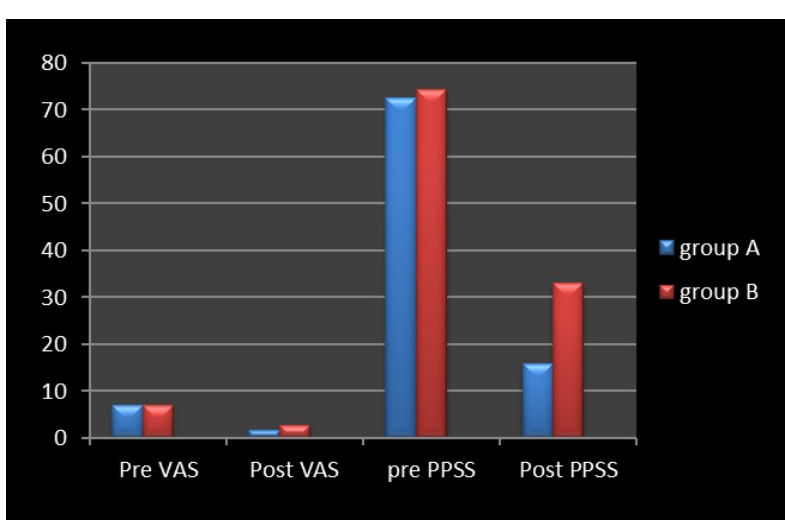

Fig 2: Average VAS and PPSS score of subjects Pre and Post intervention.

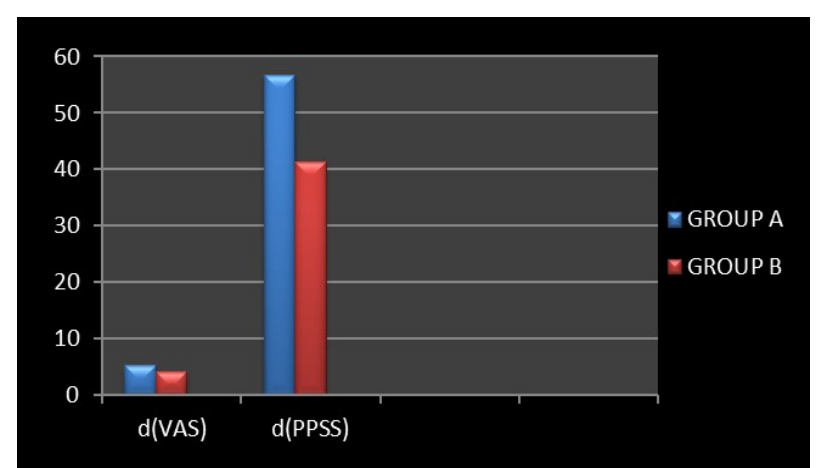

Fig 3: Difference (d) in VAS and PPSS of both the groups Pre and Post intervention.

\section{DISCUSSION}

The overall purpose of our study was to compare the influence of core strengthening program using swiss ball vs. traditional core strengthening techniques on functional impairments in amateur marathon runner having PFPS. In various other preconditions, it has been proved that core strengthening has an effect on improving pain and other functional impairments in patients with PFPS but there is no published researched which compares which technique of core strengthening is effective in improving functional impairments in marathon runners with PFPS. Since individuals with PFPS have shown a different recruitment pattern and reduced proximal stability, this study exclusively worked on improving proximal stability. In patients with PFPS core strengthening could be an effective strategy to improve the condition as it increases proximal stability, as reported by Rajhani Shirazi et al.

The rationale for the protocol of core strengthening using swiss ball is that the participant had to concentrate and shift the weight in order to maintain the stability on the ball, that in turn required the muscles to work more, which did not occur in the traditional mat core strengthening exercises. This idea is supported by the work of various authors [12], who wrote that as the surface of swiss ball is unstable it takes a lot of work by muscles to maintain stability, neuromuscular system function improves and overall postural is maintained which never occurs in traditional floor ex, who wrote that as the surface of swiss ball is unstable it takes a lot of work by muscles to maintain stability, neuromuscular system function improves and overall postural is maintained which never occurs in traditional floor exercises as the surface is stable.

The recruitment pattern of the core muscles was increased in group $A$ as the surface was unstable. The increased muscle activity in group A can also be due to increased perturbation on swiss ball, limited base of support, less contact area. As the bodily position of participants in group $A$ was more vertical as compared to the participants in group B (mat exercises), it required more muscle work for the group A participants to stabilize the spine. Ajesh Jacob in his study postulated that performing resistance exercises on an unstable surface like swiss ball may look similar to the exercises that are performed on mat but it differs in the underlying neural adaptation nature. Recruitment pattern in swiss ball exercises are efficient than mat exercises. Synchronization of motor units is noted along with lowering of the inhibitory reflexes and proprioceptive feedback is altered.

Both the protocols of group A and group B showed significant improvement, but the former group showed more improvement than the latter.

Limitations: The limitations of this study are that only amateur marathon runners were included in this study. The male and female subjects were no separated. Core muscle strength was not measured as it was not the objective of this study. The amount of muscle activity was not quantified by using electromyography biofeedback. Other factors that are required to assess in a runner like speed, balance, agility and motor control were not considered. 


\section{CONCLUSION}

Core muscle strengthening using swiss ball is more effective than traditional core muscle strengthening using a mat on functional impairments in amateur marathon runners with Patellofemoral Pain Syndrome. Within a short period of time, swiss ball training can be a treatment of choice to effectively improve core strength in marathon runners.

\section{ABBREVATIONS}

VAS - Visual Analogue Scale

PFPS - Patellofemoral Pain Syndrome

PPSS - Patellofemoral Pain Severity scale

\section{Conflicts of interest: None}

\section{REFERENCES}

[1]. Piva, S. R., Fitzgerald, G. K., Irrgang, J. J., Fritz, J. M., Wisniewski, S., McGinty, G. T., Childs, J. D., Domenech, M. A., Jones, S., \& Delitto, A. Associates of physical function and pain in patients with patellofemoral pain syndrome. Archives of physical medicine and rehabilitation, 2009;90(2):285295.

[2]. Piva SR, Gil AB, Moore CG, Fitzgerald GK. Responsiveness of the activities of daily living scale of the knee outcome survey and numeric pain rating scale in patients with patellofemoral pain. J Rehabil Med. 2009;41(3):129-135.

[3]. Cowan SM, Crossley KM, Bennell KL. Altered hip and trunk muscle function in individuals with patellofemoral pain. $\mathrm{Br} J$ Sports Med. 2009;43(8):584-588.

[4]. Almeida GP, Silva AP, França FJ, Magalhães MO, Burke TN, Marques AP. Q-angle in patellofemoral pain: relationship with dynamic knee valgus, hip abductor torque, pain and function. Rev Bras Ortop. 2016;51(2):181-186.

[5]. Willson JD, Davis IS. Lower extremity strength and mechanics during jumping in women with patellofemoral pain. J Sport Rehabil. 2009;18(1):76-90.

[6]. Prins MR, van der Wurff P. Females with patellofemoral pain syndrome have weak hip muscles: a systematic review. Aust J Physiother. 2009;55(1):9-15.
[7]. Willson JD, Kernozek TW, Arndt RL, Reznichek DA, Scott Straker J. Gluteal muscle activation during running in females with and without patellofemoral pain syndrome. Clin Biomech (Bristol, Avon). 2011;26(7):735-740.

[8]. Citaker S, Kaya D, Yuksel I, et al. Static balance in patients with patellofemoral pain syndrome. Sports Health. 2011;3(6):524-527.

[9]. Arun B, Vakkachan T, Abraham B. Comparison of dynamic postural control with and without patellofemoral pain syndrome using star excursion balance test. Journal of Medical Science and Technology. 2013;2:1-6.

[10]. Chuter VH, de Jonge XA. Proximal and distal contributions to lower extremity injury: a review of the literature. Gait \& posture. 2012 May 1;36(1):7-15.

[11]. S Mistry D, Chilgar L, Kumar A. Prevalence of Anterior Knee Pain in Marathon Runners. Website: www. ijpot. com. 2018 Jan;12(1):82.

[12]. Waryasz, G.R., McDermott, A.Y. Patellofemoral pain syndrome (PFPS): a systematic review of anatomy and potential risk factors. Dyn Med 2008;7:9.

[13]. Clement DB, Taunton JE, Smart GW, McNicol KL. A survey of overuse running injuries. The Physician and Sportsmedicine. 1981 May 1;9(5):47-58.

[14]. Carry PM, Kanai S, Miller NH, Polousky JD. Adolescent patellofemoral pain: a review of evidence for the role of lower extremity biomechanics and core instability. Orthopedics. $2010 \mathrm{Jul}$ 1;33(7):498-507.

[15]. Stefanyshyn DJ, Stergiou P, Lun VM, Meeuwisse WH, Nigg BM. Knee joint moments and patellofemoral pain syndrome in runners part i: a case control study; part ii: a prospective cohort study. Footwear Biomechanics. 1999.

[16]. Thomeé R, Augustsson J, Karlsson J. Patellofemoral pain syndrome. Sports medicine. 1999 Oct 1;28(4):245-62.

[17]. Srivastav P, Nayak N, Nair S, Sherpa LB, Dsouza D. Swiss Ball Versus Mat Exercises For Core Activation of Transverse Abdominis in Recreational Athletes. J Clin Diagn Res. 2016;10(12):YC01-YC03.

[18]. Mellinger S, Neurohr GA. Evidence based treatment options for common knee injuries in runners. Annals of translational medicine. 2019 Oct; 7 (Suppl 7).

\section{How to cite this article:}

Simran R. Sachadev, Ronald N Prabhakar, Manal M Anthikat. Effectiveness of Core Muscle Strengthening using Swiss Ball vs Traditional Core muscle Strengthening Exercises on Functional Impairments in Amateur Marathon Runners with Patellofemoral Pain Syndrome. Int J Physiother Res 2021;9(4):3937-3943. DOI: 10.16965/ijpr.2021.153 